\title{
Biomorphous SiC ceramics prepared from cork oak as precursor
}

\author{
V.S. Kiselov ${ }^{\mathrm{a}}$, V.O. Yukhymchuk ${ }^{\mathrm{a}, *}$, M.Ya. Valakh ${ }^{\mathrm{a}}$, M.P. Tryus ${ }^{\mathrm{a}}$,

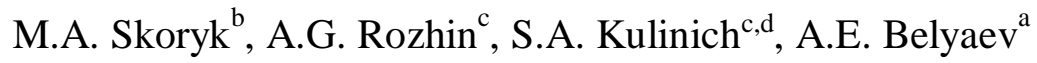 \\ ${ }^{\mathrm{a}}$ V. Lashkaryov Institute of Semiconductor Physics, NAS of Ukraine; 41, Prospect Nauky, 03028 Kyiv, Ukraine \\ ${ }^{\mathrm{b}}$ Nanomedtech LLC, 68, Gorky Str., 03680 Kyiv, Ukraine \\ ${ }^{\mathrm{c}}$ School of Engineering and Applied Science, Aston University, Aston Triangle, Birmingham, B4 7ET, UK \\ ${ }^{\mathrm{d}}$ Institute of Innovative Science and Technology, Tokai University, Hiratsuka, Kanagawa, 259-1292, Japan
}

\begin{abstract}
.
Porous ceramic materials of $\mathrm{SiC}$ were synthesized from carbon matrices obtained via pyrolysis of natural cork as precursor. We propose a method for the fabrication of complex-shaped porous ceramic hardware consisting of separate parts prepared from natural cork. It is demonstrated that the thickness of the carbon-matrix walls can be increased through their impregnation with Bakelite phenolic glue solution followed by pyrolysis. This permits to modify the mechanical and thermophysical properties of the prepared SiC ceramics. Both the carbon matrices (resulted from the pyrolysis step) and the $\mathrm{SiC}$ ceramics are shown to be pseudomorphous to the structure of initial cork. Depending on the synthesis temperature, $3 \mathrm{C}-\mathrm{SiC}, 6 \mathrm{H}$-SiC, or a mixture of these polytypes, can be obtained. By varying the mass ratio of initial carbon and silicon components, stoichiometric $\mathrm{SiC}$ or $\mathrm{SiC}: \mathrm{C}: \mathrm{Si}, \mathrm{SiC}: \mathrm{C}$, and $\mathrm{SiC}: \mathrm{Si}$ ceramics could be produced. The structure, as well as chemical and phase composition of the prepared materials were studied by means of Raman spectroscopy and scanning electron microscopy.
\end{abstract}

Keywords: biomorphous $\mathrm{SiC}$ ceramics, cork, pyrolysis, $\mathrm{SiC}$ synthesis, Raman scattering, scanning electron microscopy.

\footnotetext{
* Corresponding Author: yukhym@isp.kiev.ua (V.O. Yukhymchuk)
} 


\section{Introduction}

SiC-based ceramic materials are widely applied in machinery manufacturing, power electronics, nuclear power engineering, military and space industry, and so on. [1-5]. This is greatly determined by their unique properties such as low thermal expansion coefficient, high resistivity to oxidation, high thermal conductivity and mechanical strength in a broad temperature range (up to $1500^{\circ} \mathrm{C}$ ), chemical stability and radiation strength. Combination of the properties of a porous carbon structure [6] and those of SiC makes such materials even more unique. Therefore, synthesis of porous $\mathrm{SiC}$ ceramics requires search for plants (so-called "templates") with an internal structure optimal for devices designed for specific applications.

The latter search for proper plants was the stimulus that inspired and propelled the development of the technology (related to the fabrication of porous biomorphous $\mathrm{SiC}$ ceramics) for two recent decades [7-27]. The technology itself is based on two processes: (1) fabrication of carbon matrices from various plant species upon pyrolysis in an inert atmosphere; (2) subsequent impregnation of thus-prepared matrices with liquid [8] or gaseous [20] silicon. Importantly, the thussynthesized ceramics are pseudomorphous to the initial biological objects on the micro-, meso- and macroscale $[7,9,24]$.

The latter pseudomorphousness is of special importance for many applications. For example, fabrication of high-temperature filters requires a uniform distribution of pores over the filtering material surface, which provides uniform distribution of the filtered liquid or gas over the whole cross-section [7, 14]. Another important parameter in this case is a large area of the inner surface of the pores where the liquid or the gas molecules can be adsorbed [7, 15]. In addition, filters for liquid metals are also required to demonstrate high corrosion resistance [7].

Porous $\mathrm{SiC}$ ceramics can serve as a basis for the fabrication of thermal shields, for which stability at high temperatures is important $[6,7,28]$. Another important application field for such porous materials is their being support for catalysts. The main requirement here is also a large effective surface area, while high thermal stability, chemical inertness, and high mechanical strength are also of great importance $[16,17]$.

Preparation of porous $\mathrm{SiC}$ ceramics with the above mentioned properties often requires a template plant that possesses a structure with high porosity and similar pore sizes, with the pores being uniformly distributed over the cross-section. That is why in this work, we have used samples 
of cork made of bark of the cork oak (growing in the southwest Europe and northwest Africa) as the initial material.

The special feature of the cork material that makes it ultra-light and provides with low thermal conductivity is its honeycomb structure [29]. In order to produce large-area wares, cork granules from 0.25 to $8 \mathrm{~mm}$ in size are often used. The granules are put together by means of cork powder and India rubber or glue. On the other hand, such properties of the cork material as its large effective area of inner surface, homogeneous distribution of pores over the cross-section, as well as their narrow size distribution, form a basis for the fabrication of a great variety of modern highly technological wares mentioned above.

The present work aimed at elaborating a technological process for the fabrication of porous $\mathrm{SiC}$ ceramic materials from the natural cork and studying their properties. Two cork-based materials, bulk and granulated cork plates, were used as precursors for obtaining SiC ceramics, while Raman spectroscopy was applied as the primary technique to characterize the structure of product and its composition.

\section{Experimental}

Typically, biomorphous SiC ceramics are prepared via the two-step strategy that includes: (i) preparation of carbon-based matrix through the pyrolysis of a biological precursor material (traditionally from plants) in an inert atmosphere followed by (ii) impregnation with silicon and thus fabrication of a $\mathrm{SiC}$ ceramic that morphologically resembles the initial material $[6,7,26,27]$. In this work, we used two types of cork materials (natural cork plates and samples made of separate granules) as templates to prepare carbon matrices. The samples of both types were heated for $6-8 \mathrm{~h}$ in a horizontal quartz tube-shaped oven with an argon flow of $\sim 10 \mathrm{~cm}^{3} / \mathrm{min}$. To avoid destruction of the internal structure of the samples under heating, the temperature at the initial stage of pyrolysis was elevated rather slowly $\left(\sim 1-2^{\circ} \mathrm{C} / \mathrm{min}\right)$. Upon reaching $400{ }^{\circ} \mathrm{C}$, the heating rate was increased to 5$6{ }^{\circ} \mathrm{C} / \mathrm{min}$. Finally, the samples were kept at $900{ }^{\circ} \mathrm{C}$ for $1 \mathrm{~h}$, after which they were slowly cooled down to room temperature.

To transform the as-obtained carbon matrices into $\mathrm{SiC}$, they were impregnated with liquid silicon $[6,7,26]$. This process was carried out in two stages. First the carbon matrices and silicon were placed in a crucible made of dense carbon and slowly heated at low argon pressure (200300 mbar) up to $T_{1}=1450-1550{ }^{\circ} \mathrm{C}$. The duration of the first stage was $10-20 \mathrm{~min}$. Note that at this stage the pyrolysis of parts of the samples which had not been fully transformed into carbon earlier 
could be completed. At the second stage, the argon gas was pumped out and the temperature was raised to $T_{2}=1550-2100{ }^{\circ} \mathrm{C}$. The duration of this stage was varied between 30 to $120 \mathrm{~min}$. Depending on the initial $\mathrm{C}$ to $\mathrm{Si}$ mass ratio, as well as the processing time and temperature, the final product could be either stoichiometric $\mathrm{SiC}$ or $\mathrm{SiC} / \mathrm{C}$ or $\mathrm{SiC} / \mathrm{Si}$ composites. If necessary, the excessive carbon in the as-prepared $\mathrm{SiC} / \mathrm{C}$ composites was eliminated in oxygen atmosphere at $900{ }^{\circ} \mathrm{C}$ for $2 \mathrm{~h}$ (as an additional step).

The structure and composition of the obtained materials were studied by Raman spectroscopy (RS). The Raman spectra were excited by an $\mathrm{Ar}^{+}$laser with the wavelength of $514 \mathrm{~nm}$ and were recorded at room temperature in a Raman System 1000 spectrometer from Renishaw. The sample morphology at various stages of fabrication was followed by optical microscopy and scanning electron microscopy (SEM, Tescan Mira 3 LMU).

\section{Results and discussion}

The pyrolysis processes carried out at temperatures above $600{ }^{\circ} \mathrm{C}$ are known to result in the decomposition of organic substances within the template plant material. At this stage $\mathrm{H}_{2} \mathrm{O}, \mathrm{CO}_{2}$, organic acids, carbonyl groups, and alcohols are removed from the sample, while main biopolymers contained in the cell walls of the heat-treated material rearrange and are gradually transformed into carbon-based frameworks pseudomorphous to those of the initial plant structures. In natural cork the pores are known to be closed [29]. An important result of the heat-treatment related processes is the wall destruction in the closed pores that are initially bubble-shaped. As a result, after pyrolysis the as-obtained carbon matrices possess open porosity, which makes them attractive for applications as filters $[6,7,15]$, catalyst supports [16, 17], supercapacitor electrodes [18], as well as templates for their subsequent impregnation by liquid silicon and preparation of $\mathrm{SiC}$ ceramics.

Figure 1 presents the surface images of plates obtained from the natural cork material (a), made of separate cork granules (b), as well as those of carbon matrices (c and d) resulted from their pyrolysis. In many cases, the pyrolysis process is seen in Fig.1d to result in the disintegration of the granulated material into separate granules. This can be explained by the expansion of the resulted material by approximately $20 \%$ compared to its biological precursor taken for pyrolysis. This makes ceramics derived from the cork material considerably distinct from their counterparts produced via the same technique from other wood species, as the latter were observed to shrink during pyrolysis $[26,27]$. 
Figure 2a exhibits an SEM surface image of a carbon matrix as-obtained after the pyrolysis of natural cork. The morphology of the sample is clearly seen to be characterized by hexagon-shaped pores with sizes between 30 and $50 \mu \mathrm{m}$ well distributed all across the sample, implying that the carbon-based matrix inherited the structure of the initial cork material. It is noteworthy that the minimum wall thickness in the matrix made of natural cork is rather small, being only about $100 \mathrm{~nm}$ (Fig. 2 b).

As our results demonstrated (see below), the impregnation of the carbon matrices (prepared via pyrolysis) with liquid silicon gives rise to $\mathrm{SiC}$ materials, while the matrix structure itself gets somewhat destroyed during this process. As an example, the SEM image in Fig.3a demonstrates that the sizes of $\mathrm{SiC}$ crystals formed in a ceramic formed at $1700{ }^{\circ} \mathrm{C}$ for $30 \mathrm{~min}$ were as big as $1-5 \mu \mathrm{m}$, which considerably larger than the wall thickness in the initial carbon matrix. Since the carbon wall thickness was $\sim 100 \mathrm{~nm}$ and the average density of carbon is $2.25 \mathrm{~g} / \mathrm{cm}^{3}$, then for the $3 C$-SiC, whose density is $3.21 \mathrm{~g} / \mathrm{cm}^{3}$, the thickness of the continuous layer cannot exceed $\sim 70 \mathrm{~nm}$. Therefore, when $\mathrm{SiC}$ is being synthesized and the crystal size reaches $2-3 \mu \mathrm{m}$, voids are formed between the crystals, which leads to the destruction of the inner structure of the sample. Using shorter synthesis times gives rise to SiC crystals with smaller sizes; however, according to Raman analysis, such samples keep some fraction of unreacted $\mathrm{Si}$ and $\mathrm{C}$ phases. Thus, it is quite difficult to choose appropriate processing conditions that would provide both tightly connected small SiC crystals (as walls) and the absence of unreacted silicon and carbon in the produced ceramic material.

On the other hand, to avoid any destruction of the $\mathrm{SiC}$ ceramic during its formation, its wall thickness should be increased. This was achieved via the impregnation of the as-prepared carbon matrix with a bakelite phenolic glue followed by a subsequent drying stage at $300{ }^{\circ} \mathrm{C}$ during $3 \mathrm{~h}$. It is seen in Fig. 2 that the minimal wall thickness after this procedure increased to $\sim 2 \mu \mathrm{m}$. The $\mathrm{SiC}$ ceramics prepared from such carbon matrices with reinforced walls did not reveal any signs of destruction of their structure (Fig. 3c). Moreover, the application of such a Bakelite phenolic glue permits to put together (and keep during further impregnation with $\mathrm{Si}$ and high-temperature treatment) separate cork items of various shapes, which is of high importance when samples with complex shapes are to be prepared (Fig. 3b). Our experiments demonstrated that parts of complex samples could be glued up together both before the pyrolysis stage and after it.

Both the intermediate carbon structures and final SiC ceramic products were studied in detail by Raman spectroscopy at various stages of the process. Figure 4 shows three Raman spectra of a carbon matrix formed from the cork after pyrolysis at $900{ }^{\circ} \mathrm{C}$ for 1 hour. The spectra $1-3$ were obtained using varied excitation power of laser beam $(0.01,0.1$ and $1 \mathrm{~mW}$, respectively). It clearly 
seen in Fig. 4 that two broad bands at $\sim 1355$ and $\sim 1580 \mathrm{~cm}^{-1}$ were observed in the carbon matrix spectra. These so-called D and G bands are well-known to correspond to the vibrational modes of $\mathrm{sp}^{2}$-hybridized carbon [30-33]. The $\mathrm{G}$ band at $1580 \mathrm{~cm}^{-1}$, also known as the graphite band, results from the doubly degenerate mode of $E_{2 g}$ and corresponds to stretching vibrations of all pairs of carbon atoms in the benzene rings [31-33]. The D band is caused by the Brillouin zone-edge $A_{1 g}$ breathing mode of the 6-atom benzene rings. It is not revealed in the Raman spectra of defect-free carbon structures since it is forbidden by the selection rules [31-32].

The spectra presented in Fig. 4 allow us to conclude that the structure of the carbon matrices produced via the pyrolysis of precursor cork material corresponds to that of partially disordered graphite. It is seen from the spectra that an increase of the laser power from 0.01 to $0.1 \mathrm{~mW}$ (curve 2), in addition to a considerable increase in the D and G band intensities, results in their slight downward shift by $2 \mathrm{~cm}^{-1}$. Further power increase up to $1 \mathrm{~mW}$ was found to lead to a noticeable decrease of the band intensities and their further downward shift by $14 \mathrm{~cm}^{-1}$ (curve 3 in Fig. 4). The latter essential decrease of the band intensity and their noticeable low-frequency shift are believed to be a result of intense heating of the carbon matrix due to its very low thermal conductivity caused by its high porosity and thin walls between cells.

Figure 5 presents Raman spectra of SiC ceramics prepared via impregnation of carbon matrices with liquid silicon at different temperatures (a) and using different $\mathrm{C} / \mathrm{Si}$ ratios during impregnation (b). The analysis of the spectra using phonon frequencies known for various $\mathrm{SiC}$ polytypes shows that all samples synthesized within the temperature range from 1550 to $1700{ }^{\circ} \mathrm{C}$ correspond to the $3 \mathrm{C}$-SiC polytype. At synthesis temperatures above $1700{ }^{\circ} \mathrm{C}$, the $6 \mathrm{H}$-SiC polytype is known to form [26, 27], and thus samples with Raman bands corresponding to both polytypes were expected. Indeed, as clearly seen in Fig. 5a, the sample formed at $1700{ }^{\circ} \mathrm{C}$ was of $3 C$-SiC type (spectrum 1), with its characteristic TO and LO phonon band frequencies at 797 and $937 \mathrm{~cm}^{-1}$, respectively. At the same time, the TO band in spectrum 1 is somewhat asymmetric at its highfrequency side and has a shoulder at its low-frequency side, which implies a slight contribution of the $6 \mathrm{H}$-SiC polytype in the Raman scattering of the sample. For comparison, the sample prepared at 2100 ${ }^{\circ} \mathrm{C}$ is seen to be dominated exclusively by the $6 H$ polytype (Fig. $5 \mathrm{a}$, spectrum 2 ).

Figure 5b shows Raman spectra of several biomorphous $\mathrm{SiC}$ ceramics obtained at various mass $\mathrm{C} / \mathrm{Si}$ ratios used during the impregnation stage: 2.33 (spectra 1,2), > 2.33 (spectrum 3), and $<2.33$ (spectrum 4). The analysis of the spectra implies that the prepared ceramic samples were sensitive not only to their preparation temperature but also to the component ratio $(\mathrm{C} / \mathrm{Si})$ used during 
the impregnation stage. At the mass ratio $\mathrm{C} / \mathrm{Si}$ of 2.33, stoichiometric $\mathrm{SiC}$ materials should be formed [27]. However, when the process temperature or process duration are insufficient to involve all $\mathrm{C}$ and $\mathrm{Si}$ atoms in the reaction, $\mathrm{SiC}: \mathrm{C}: \mathrm{Si}$ ceramics are formed. This case corresponds to curve 1 in Fig. $5 \mathrm{~b}$. Indeed, the corresponding spectrum contains the characteristic bands of three different components of the ceramics: $\mathrm{Si}-\mathrm{Si}$ vibrations in the range of $\sim 520 \mathrm{~cm}^{-1}$ corresponding to silicon [27], the D (1350 $\left.\mathrm{cm}^{-1}\right)$ and $\mathrm{G}\left(1580 \mathrm{~cm}^{-1}\right)$ bands corresponding to the $\mathrm{C}-\mathrm{C}$ vibrations in the carbon clusters [27] and very weak TO $\left(\sim 800 \mathrm{~cm}^{-1}\right)$ and $\mathrm{LO}\left(\sim 960 \mathrm{~cm}^{-1}\right)$ bands corresponding to the $\mathrm{SiC}$ vibrations modes [27]. An increase in synthesis temperature results in an increase in the SiC TO phonon band intensity and a relative decrease in intensities of the bands corresponding to the $\mathrm{Si}-\mathrm{Si}$ and $\mathrm{C}-\mathrm{C}$ vibrations (Fig. 5 , b, curve 2). Besides, as clearly seen in Fig. 5b (spectra 2-4), additional second-order SiC bands around $1550 \mathrm{~cm}^{-1}$ appear in the range of the $\mathrm{C}-\mathrm{C}$ vibrations [34]. For the case when the initial component ratio $\mathrm{C} / \mathrm{Si}$ was larger than 2.33 (Fig. 5b, curve 3), the Raman spectrum only contains the bands corresponding to the $\mathrm{C}-\mathrm{C}$ vibrations, as well as those characteristic of $\mathrm{SiC}$ (TO $\sim 800 \mathrm{~cm}^{-1}$ and LO $\sim 960 \mathrm{~cm}^{-1}$ ). For $\mathrm{C} / \mathrm{Si}<2.33$ (Fig. 5b, curve 4), the spectrum contains bands resulting from the $\mathrm{Si}-$ Si vibrations $\left(\sim 520 \mathrm{~cm}^{-1}\right)$ in the silicon clusters and the $\mathrm{SiC}$ TO phonon band $\left(\sim 800 \mathrm{~cm}^{-1}\right)$. The LO phonon band intensity depends on synthesis conditions, and the presence of defects in the synthesized crystals results in a considerable decrease of its intensity. Thus, we demonstrate here that changing the initial component mass ratio $\mathrm{C} / \mathrm{Si}$, it is possible to obtain stoichiometric $\mathrm{SiC}$, as well as $\mathrm{SiC}: \mathrm{C}: \mathrm{Si}$; $\mathrm{SiC}: \mathrm{C}$, and $\mathrm{SiC}: \mathrm{Si}$, ceramics. At the same time, changing the process temperature from 1550 to $2100{ }^{\circ} \mathrm{C}$, either $3 C$-SiC or a mixture of $3 C$ and $6 H$ polytypes or $6 H \mathrm{SiC}$ can be obtained. Note that obtaining porous $\mathrm{SiC}$ : $\mathrm{C}$ : $\mathrm{Si}$ and $\mathrm{SiC}$ : $\mathrm{Si}$ composites with a large internal surface area are important for the production of anodes in high-performance lithium ion batteries [35, 36].

Based on the above results, a simple and efficient approach for the fabrication of $\mathrm{SiC}$ ceramics using natural oak cork material as precursor is proposed. It consists of several technological stages shown in Fig. 6. During stage (1), plates of natural cork are subjected to pyrolysis in an inert atmosphere (argon, nitrogen). Then at stage (2), Bakelite phenolic glue is used to adjoin separate cork granules and/or additional elements to the initial samples and thus form a final item. As next stage (3), thickening of the carbon matrix walls is achieved via soaking the final item in a Bakelite phenolic glue. At stage (4), the intermediate product is dried at $300{ }^{\circ} \mathrm{C}$ and, if necessary, annealed for additional pyrolysis. Finally, at stage (5), SiC ceramics are synthesised via impregnation of the carbon matrices with liquid silicon at temperatures above $1550{ }^{\circ} \mathrm{C}$ for $30-120 \mathrm{~min}$ and using the component mass ratio $\mathrm{C} / \mathrm{Si}$ of 2.33. At the last stage, temperature control is important to obtain different polytypes of $\mathrm{SiC}$, while varying the $\mathrm{C} / \mathrm{Si}$ ratio is a simple means to control the final material's composition. 


\section{Conclusions}

Biomorphous $\mathrm{SiC}$ ceramics were prepared via impregnating carbon matrices formed from natural cork in the course of pyrolysis with liquid silicon. The carbon matrices and the biomorphous ceramics are shown to be pseudomorphous to the initial cork structure. The possibility of thickening the walls of the carbon frame (obtained from the cork) through additionally soaking in Bakelite phenolic glue is shown. Increasing the frame wall thickness enables one to vary the mechanical characteristics of the $\mathrm{SiC}$ ceramics and thereby to control their thermophysical properties. A technique is proposed to obtain porous ceramic items of complex shapes from separate parts preliminarily prepared from natural cork and then joined by Bakelite phenolic glue.

Raman spectroscopy studies showed that in the course of impregnation of the carbon matrices with liquid silicon in the temperature range from 1550 to $1700{ }^{\circ} \mathrm{C}$ the $3 C$-SiC polytype was formed. The synthesis of the $\mathrm{SiC}$ ceramics at temperatures above $1700{ }^{\circ} \mathrm{C}$ results in the formation of a mixture of the $3 C$ - and $6 H$-SiC polytypes, while at temperatures above $2100{ }^{\circ} \mathrm{C}$ only the $6 H$ polytype is formed. Moreover, the use of different $\mathrm{C} / \mathrm{Si}$ ratios during the impregnation of carbon matrices with liquid Si permitted to obtain either stoichiometric $\mathrm{SiC}$ or $\mathrm{SiC}: \mathrm{C}: \mathrm{Si}, \mathrm{SiC}: \mathrm{C}$, or $\mathrm{SiC}: \mathrm{Si}$ ceramics.

The SiC-based ceramics prepared on the basis of natural cork and having open pores possess a very attractive combination of properties, such as low weight, high permeability for liquids and gases, low thermal conductivity, high corrosion resistance, and high-temperature stability of the mechanical characteristics. These properties make them very promising materials for porous heaters, catalyst supports, filters for molten metals, hot liquids and gases, thermal shields and light emitters.

\section{Acknowledgments}

This work was supported by the Marie Curie International Research Staff Exchange Scheme “TelaSens” project, Research Executive Agency Grant No 269271, Programme: FP7-PEOPLE-2010IRSES. 


\section{References}

1. Properties of silicon carbide. Edited by Gary L. Harris, — United Kingdom: IEE, 1995. ISBN 0852968701.

2. Hand book of ceramic composites. Edited by Narottam P. Bansal. - Springer, 2005. ISBN 1402081332.

3. M. Willander, M. Friesel, Q.-U. Wahab, B. Straumal. Silicon carbide and diamond for high temperature device applications. J. Mater. Sci. - Mater. Electron. 17 (2006) 1- 25.

4. S. Nishino, J. Powel, N.A. Will. Production of large-area single-crystal wafers of cubic SiC for semiconductor devices. Appl. Phys. Lett. 42 (1983) 460-462.

5. D. Nakamura, I. Gunjishima, S. Yamaguchi et al. Ultrahigh-quality silicon carbide single crystals.- R\&D Review of Toyota, CRDL. 41, N 2.

6. P. Colombo. In praise of pores. Science 322 (2008) 381-383.

7. A.R. Studart, U.T. Gonzenbach, E. Tervoort, L.J. Gauckler. Processing routes to macroporous ceramics: A review. J. Am. Ceram. Soc. 89 (2006) 1771-1789.

8. J.-H. Eom, Y.-W. Kim, S. Raju. Processing and properties of macroporous silicon carbide ceramics: A review. J. Asian Ceram. Soc. 1 (2013) 220-242.

9. C. Sanchez, H. Arribart, M.M. Giraud Guille. Biomimetis mand bioinspiration as tools for the design of innovative materials and systems. Nat. Mater. 4 (2005) 277- 288.

10. Q. Wang, G.-Q. Jin, D.-H. Wang, X.-Y. Guoa. Biomorphic porous silicon carbide prepared from carbonized millet. Mater. Sci. Eng. A 459 (2007) 1-6.

11. A.R. Maddocks, A.T. Harris. Biotemplated synthesis of novel porous SiC. Mater. Lett. 63 (2009) 748-750.

12. M. Prekajski, B. Babirc, D. Buycevac, J. Pantirc, J. Gulicovski, M. Miljkovirc, B. Matovirc. Synthesis and characterization of biomorphic $\mathrm{CeO}_{2}$ obtained by using egg shell membrane as template. Process. Appl. Ceram. 8 (2014) 81-85.

13. Q. Wang, D. Wang, G.-Q. Jin, Y. Wang, X. Guo. Biomorphic SiC from lotus root. Particuology 7 (2009) 199-203.

14. M. Lopez-Alvarez, L. Rial, J.P. Borrajo, P. Gonzalez, J. Serra, E. Solla, B. Leon, J.M. Sanchez, J. Martinez Fernandez, A.R. de Arellano-Lopez, F.M. Varela-Feria. Marine precursors based biomorphic SiC ceramics. Mater. Sci. Forum 587-588 (2008) 67-71.

15. S. Kitaoka, Y. Matsushima, C. Chenand, H. Awaji. Thermal cyclic fatigue behavior of porous ceramics for gas cleaning. J. Am. Ceram. Soc. 87 (2004) 906-913. 
16. C.C. Agrafiotis, I. Mavroidis, A.G. Konstandopoulos, B. Hoffschmidt, P. Stobbe, M. Romeroand, V. Fernandez-Quero. Evaluation of porous silicon carbide monolithic honey combs as volumetric receivers/ collectors of concentrated solar radiation. Sol. Energy Mater. Sol. Cells 91 (2007) 474-488.

17. U.F. Vogt, L. Gyorfy, A. Herzog, T. Grauleand, G. Plesch. Macroporous silicon carbide foams for high temperature applications and catalyst support. J. Phys. Chem. Solids 68 (2007) $1112-1116$.

18. L. Wang, G. Mu, C. Tian, L. Sun, W. Zhou, P. Yu, J. Yin, H. Fu. Porous graphitic carbon nanosheets derived from corns talk biomass for advanced supercapacitors. ChemSusChem. 6 (2013) 880-9.

19. P. Greil, E. Vogli, T. Fey, A. Bezold, N. Popovska, H. Gerhard, H. Sieber. Effect of microstructure on the fracture behavior of biomorphous silicon carbide ceramics. J. Eur. Ceram. Soc. 22 (2002) 2697-2707.

20. V.S. Kiselov, V.A. Yukhymchyk, V.I. Poludin, M.P. Tryus, A.E. Belyaev. Biomorphic SiC from peas and beans. SPQEO. 15 (2012) 305-309

21. P. Greil. Advanced engineering ceramics. Adv. Mater. 14 (2002) 709-716.

22. J.-M. Qian, Z.-H. Jin, X.-W. Wang. Porous SiC ceramics fabricated by reactive infiltration of gaseous silicon in to charcoal. Ceram. Int. 30 (2004) 947-951.

23. O.P. Chakrabarti, H.S. Maiti, R. Majumdar. Biomimetic synthesis of cellular SiC based ceramics from plant precursor. Bull. Mater. Sci. 27 (2004) 467-470.

24. L. Esposito, D. Sciti, A. Piancastelli, A. Bellosi. Microstructure and properties of porous bSiC templated from soft woods. J. Eur. Ceram. Soc. 24 (2004) 533-540.

25. M. Presas, J.Y. Pastor, J. Llorca, A.R. de Arellano Lopez, J. Martinez Fernandez, R. Seplveda Ferrer. Microstructure and fracture properties of biomorphic SiC. Int. J. Refract. Met. Hard Mater. 24 (2005) 49-54.

26. V.S. Kiselov, P.M. Lytvyn, V.O. Yukhymchuk, A.E. Belyaev, S.A. Vitusevich. Synthesis and properties of porous SiC ceramics. J. Appl. Phys. 107 (2010) 093510.

27. V.O. Yukhymchuk, V.S. Kiselov, A.E. Belyaev, M.Ya. Valakh, M.V. Chursanova, M. Danailov, S.A. Vitusevich. Raman spectroscopy of bio-SiC ceramics. Phys. Status Solidi A 208 (2011) 808-813.

28. K.E. Pappacena, K.T. Faber. Thermal conductivity of porous silicon carbide derived from wood precursors. J. Am. Ceram. Soc. 90 (2007) 2855-2862.

29. H. Pereira (2007). Cork: biology, production and uses. Elsevier. Publications, Amsterdam.

30. F. Tuinstra, J. L. Koenig. Raman spectrum of graphite. J. Chem. Phys. 53 (1970) 1126-1130. 
31. S. Reich, C. Thomsen. Raman spectroscopy of graphite. Phil. Trans. R. Soc. Lond. A 362 (2004) 2271-2288.

32. A.C. Ferrari. Raman spectroscopy of graphene and graphite: Disorder, electron-phonon coupling, doping and nonadiabatic effects. Solid State Commun. 143 (2007) 47-57.

33. A.C. Ferrari, J. Robertson. Resonant Raman spectroscopy of disordered, amorphous, and diamond-like carbon. Phys. Rev. B 61 (2000) 14095-14107.

34. Z.C. Feng, D. Talwar, and I. Ferguson, in: Silicon Carbide Materials, Processing and Devices, Vol. 742, edited by S. E. Saddow, D. J. Larkin, N. S. Saksetal., Mater. Res. Soc. Symp. Proc. (Materials Research Society, Warrendale, PA, 2003), p. K2.14.1-6.

35. B.J. Jeon, J.K.Lee. Electrochemical characteristics of nc-Si/SiC composite for anode electrode of lithium ion batteries. J. Alloy. Compd. 590 (2014) 254-259.

36. C. Wang, Y. Li, K. Ostrikov, Y. Yang, W. Zhang. Synthesis of SiC decorated carbonaceous nanorods and its hierarchical composites Si@SiC@C for high-performance lithium ion batteries. J. Alloy. Compd. 646 (2015) 966-972. 


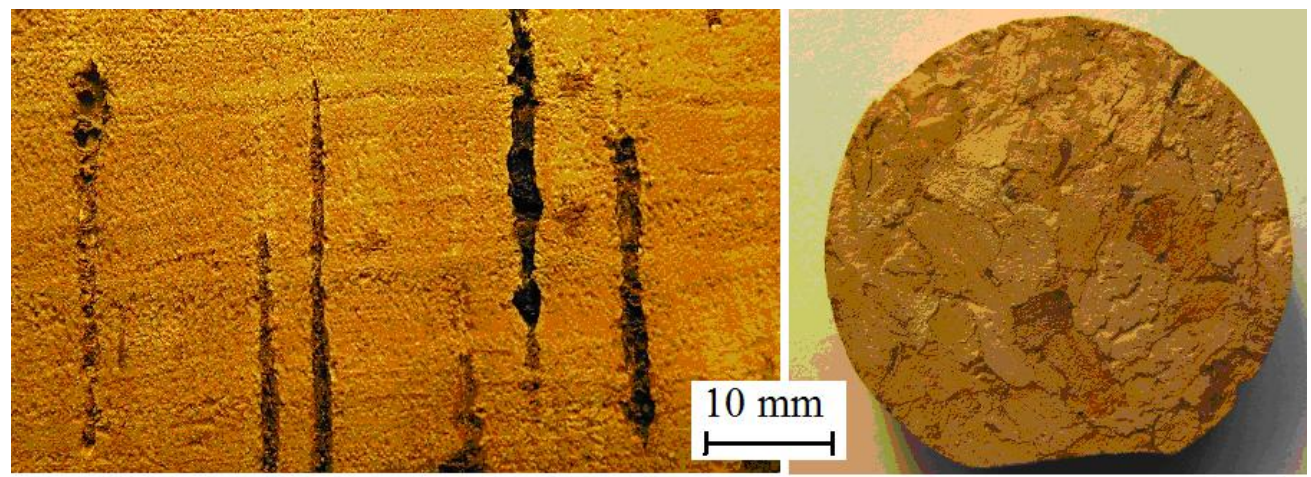

a)

b)
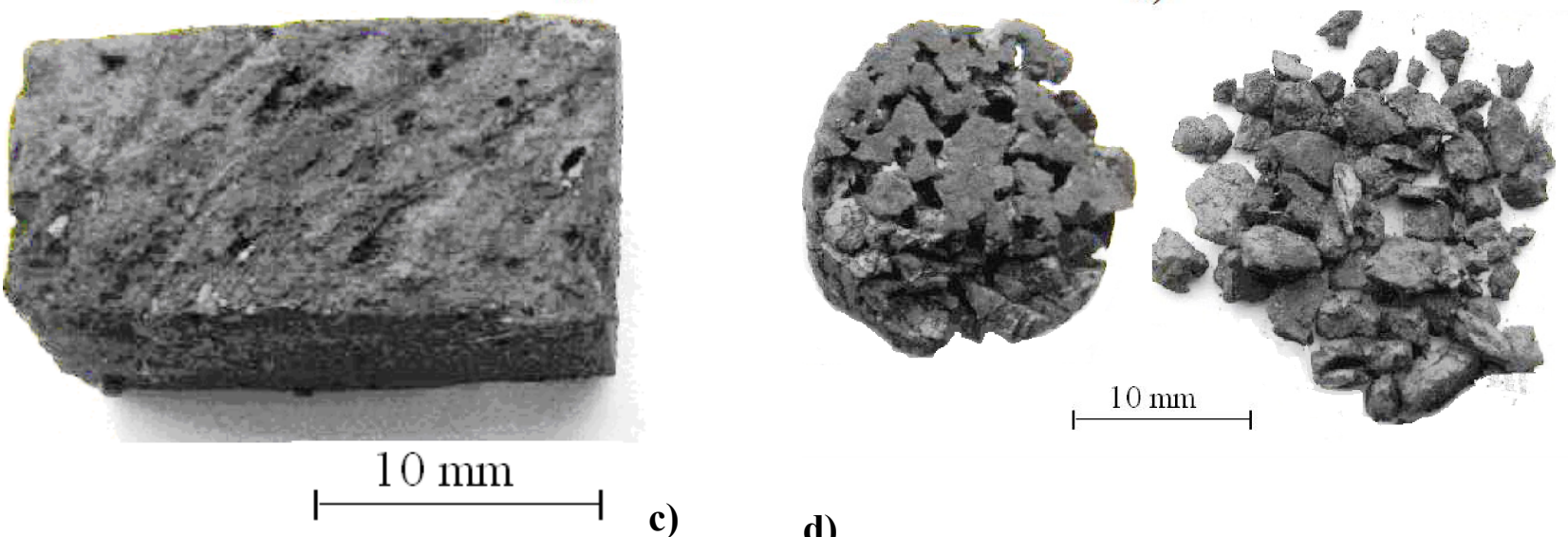

c)

d)

Fig.1. Photos of sample surfaces ( $\mathrm{a}$ - natural cork, b - granulated cork) and carbon matrices on their basis (c and d). 

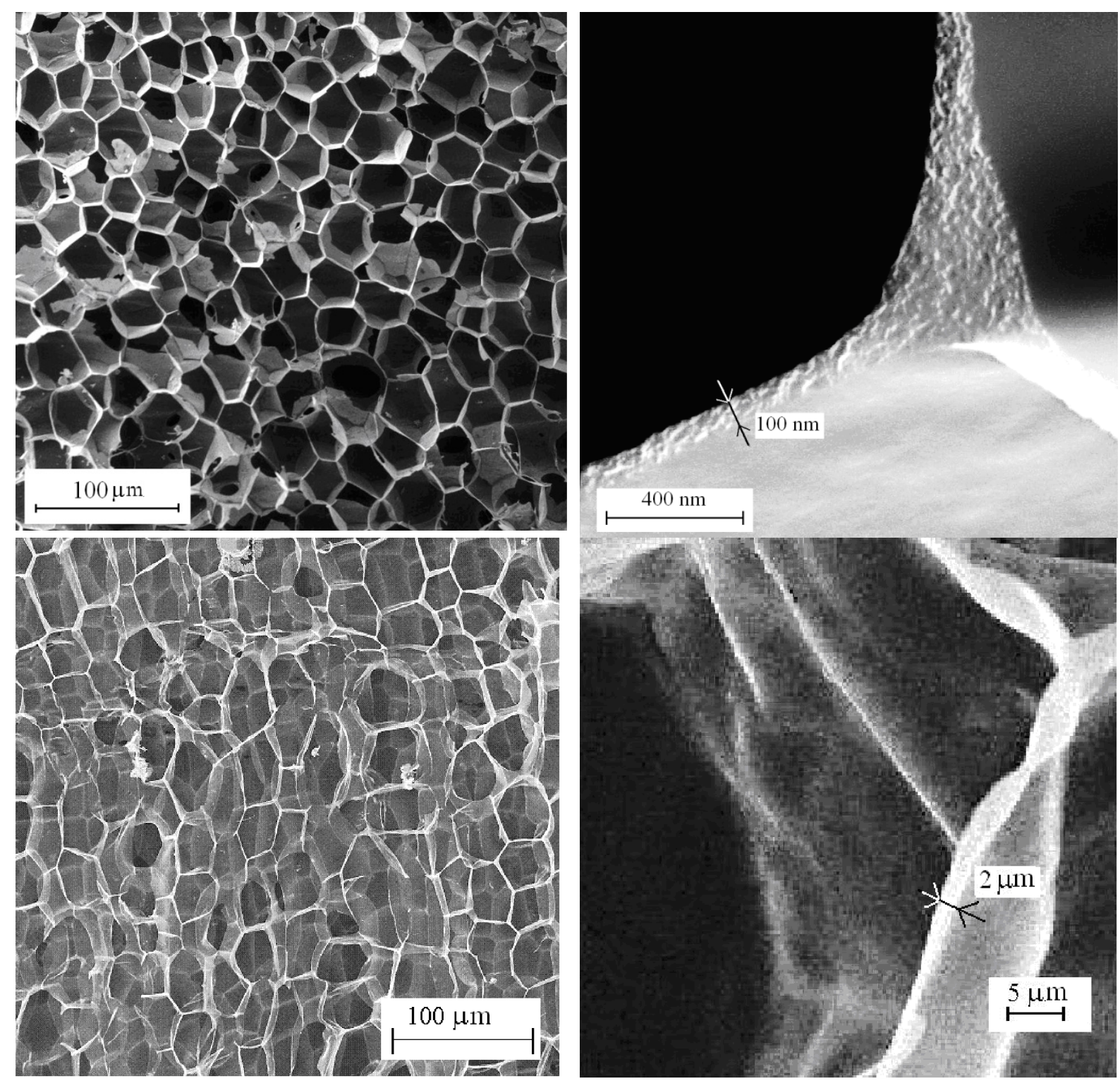

Fig. 2. SEM images of surfaces inherent to the carbon matrices prepared from: $a, b$ - natural cork; c, d - cork impregnated with bakelite-phenol glue. 


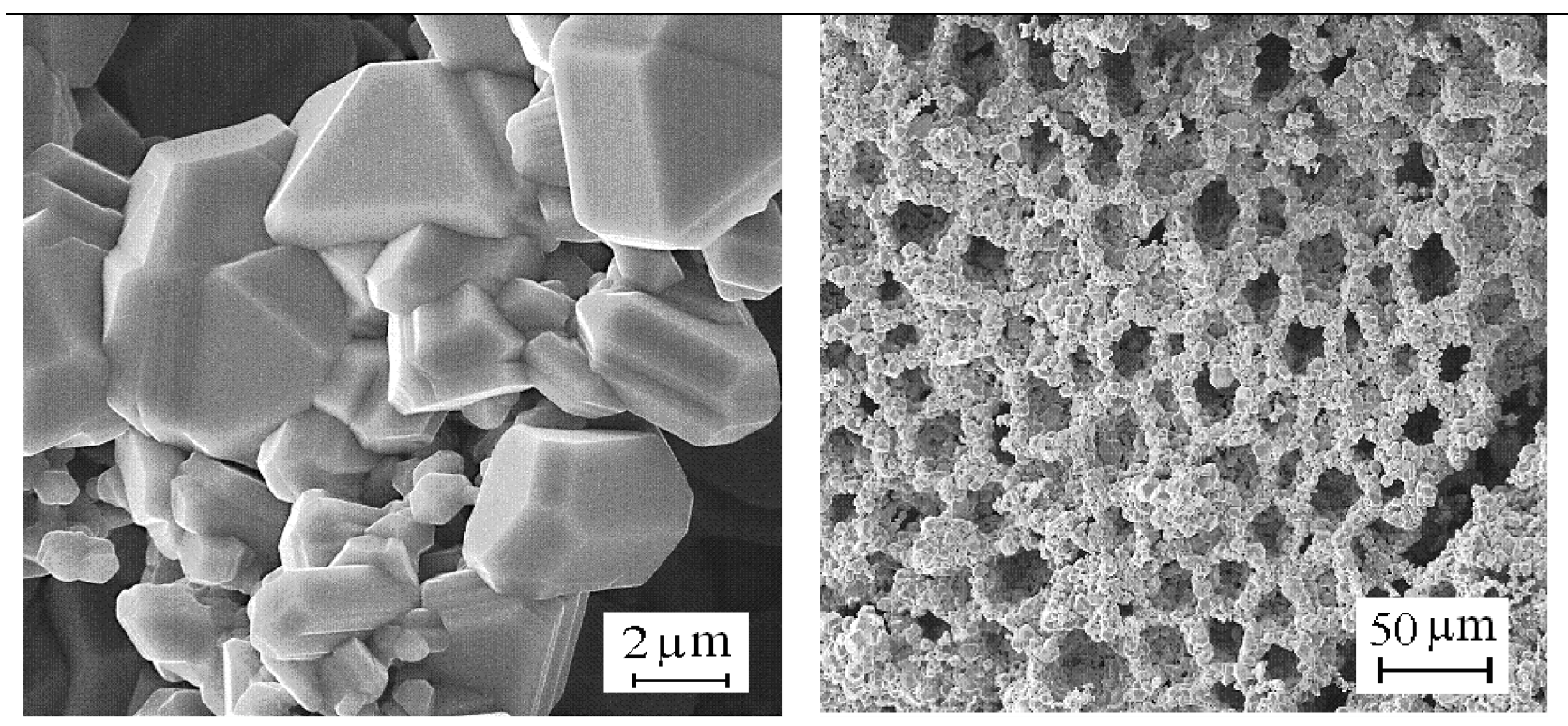

Fig. 3. Photos of the articles from granulated cork $(a, b)$ and typical SEM images of grain morphology of microcellular SiC ceramics from cork (c, d). 


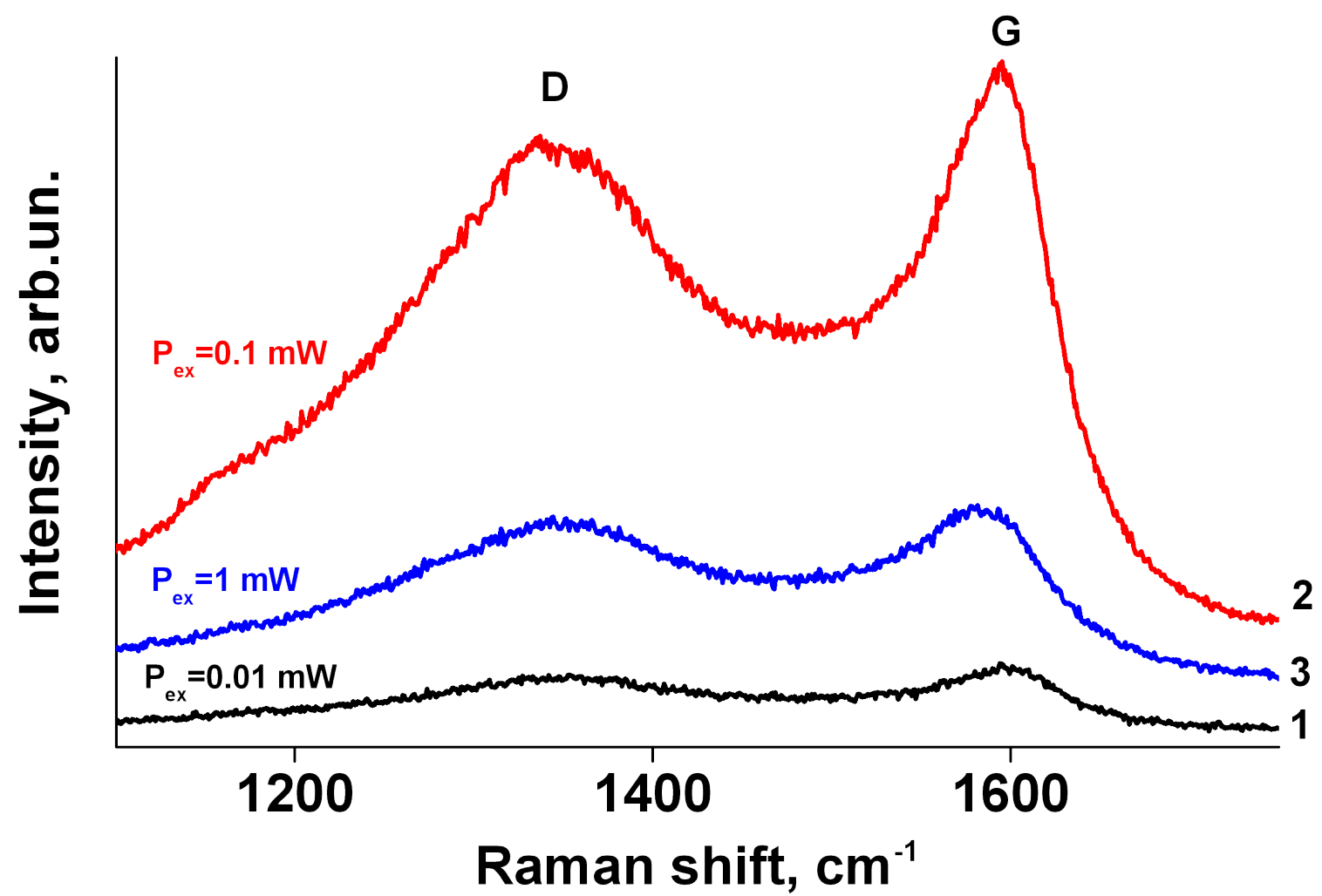

Fig. 4. Raman spectra of the carbon matrix, obtained at different laser powers and the same microscope objective $\mathrm{x} 50$. 

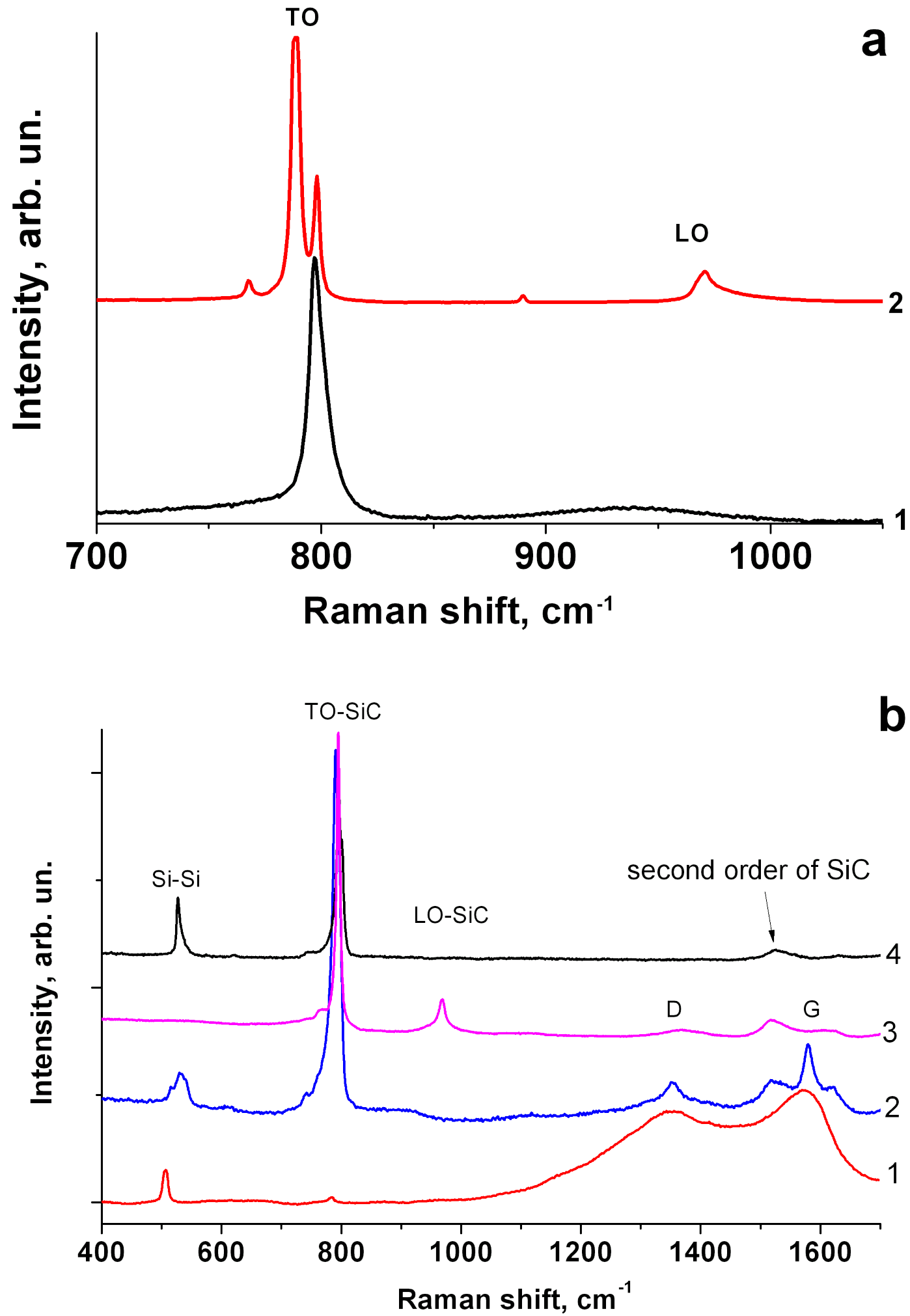

Fig. 5. Raman spectra of bio-SiC produced from cork at different temperatures (a): $\mathrm{T} \sim 1700^{\circ} \mathrm{C}$ (spectra 1) and $\mathrm{T} \sim 2100^{\circ} \mathrm{C}$ (spectra 2); (b) - influence of different mass ratios of the starting components $\mathrm{C} / \mathrm{Si}: 1-\mathrm{C} / \mathrm{Si}=2.33, \mathrm{~T} \sim 1550^{\circ} \mathrm{C}: 2-\mathrm{C} / \mathrm{Si}=2.33, \mathrm{~T} \sim 1700^{\circ} \mathrm{C} ; 3-\mathrm{C} / \mathrm{Si}>2.33, \mathrm{~T} \sim 1800^{\circ} \mathrm{C} ; 4$ - $\mathrm{C} / \mathrm{Si}<2.33, \mathrm{~T} \sim 1800^{\circ} \mathrm{C}$. 


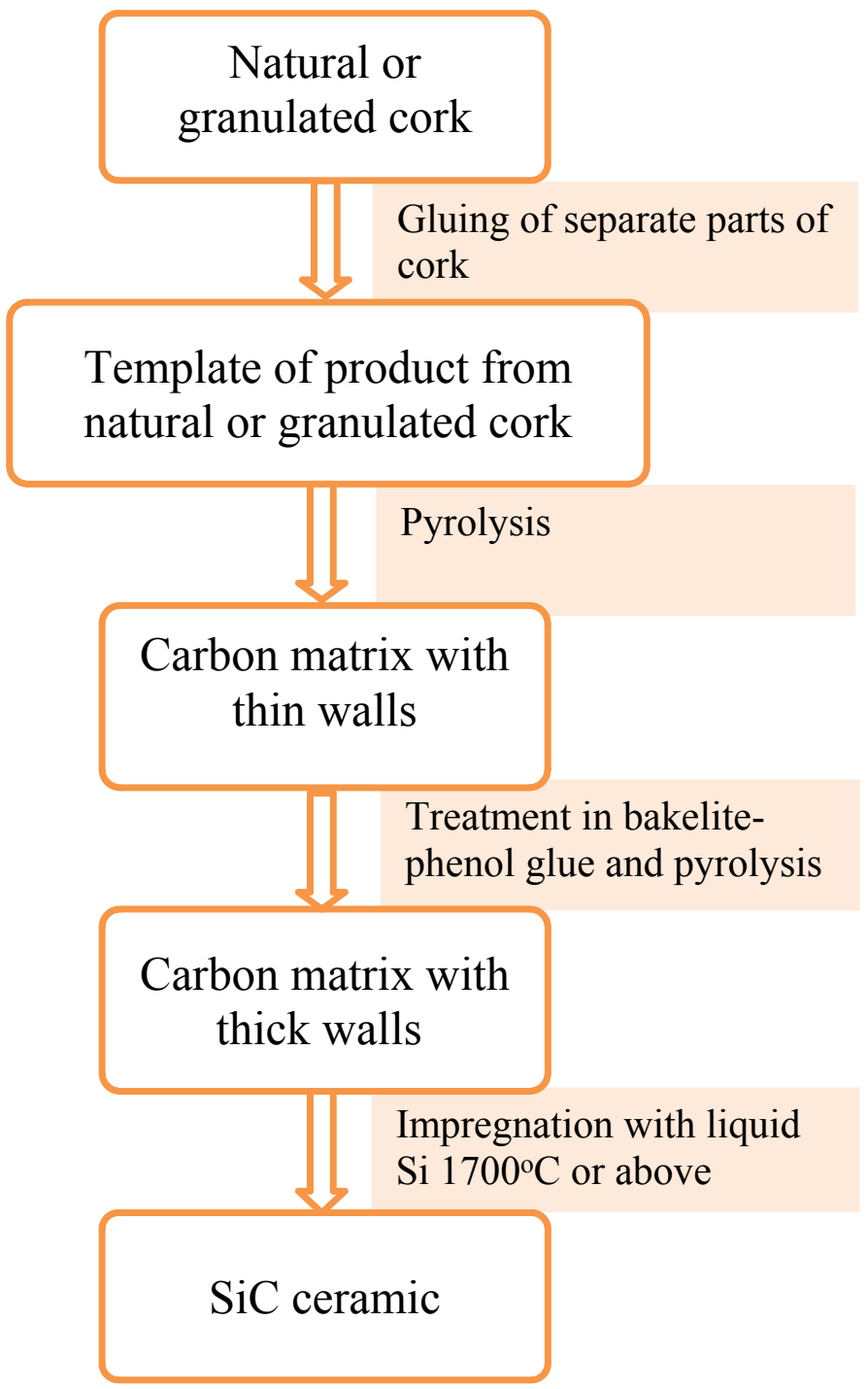

Fig.6. Processing scheme of synthesis biomorphic porous SiC ceramic derived from cork. 